\title{
GAMBARAN PELAKSANAAN TAMAN POSYANDU SEBAGAI BENTUK KEGIATAN PEMBERDAYAAN MASYARAKAT DI PUSKESMAS SIDOTOPO WETAN
}

\author{
Villia Samantha Rukmi \\ Departemen Promosi Kesehatan Dan Ilmu Perilaku, \\ Fakultas Kesehatan Masyarakat, Universitas Airlangga Surabaya \\ Email: villia.samantha@gmail.com
}

\begin{abstract}
Taman Posyandu is a service program that integrated with Pendidikan Anak Usia Dini (PAUD) and Bina Keluarga Balita (BKB). The establishment of an Integrated Service Post is intended to enable toddlers to get comprehensive services such as health information, nutritional information, parenting and obtaining protection for children. The purpose of this study was to identify a general description of the implementation of Taman Posyandu at Sidotopo Wetan Community Health Center area for community empowerment activities. The design of this study used descriptive and observational, and this research was conducted with secondary data collection, observation, and participation. Based on the data analysis, the results of the study showed that Taman Posyandu Bunda Kartini obtained the optimal value as the assessment criteria. But for Bina Keluarga Balita (BKB) services, it cannot be done optimally because the implementation cannot be done every month. Taman Posyandu Bunda Kartini is included in the UKBM because in its implementation it has included the concept of empowerment such as independence, participation, networking, and equity.
\end{abstract}

Keywords: Taman Posyandu, UKBM, Community Empowerment, Health Promotion

\begin{abstract}
ABSTRAK
Taman Posyandu adalah layanan Posyandu yang terintegrasi dengan Pendidikan Anak Usia Dini (PAUD) dan Bina Keluarga Balita (BKB). Pembentukan taman posyandu bertujuan agar balita mendapatkan layanan secara menyeluruh, baik dari kesehatan, pemenuhan gizi, pengasuhan orang tua dan memperoleh perlindungan terhadap anak. Tujuan dari penelitian ini adalah untuk mengidentifikasi gambaran umum pelaksanaan Taman Posyandu di wilayah Puskesmas Sidotopo Wetan dalam kegiatan pemberdayaan masyarakat. Desain penelitian ini menggunakan desain penelitian deskriptif dan obsevasional, dimana penelitian ini dilakukan dengan pengumpulan data skunder, observasi dan partisipasi. Berdasarkan hasil analisis data, diperoleh hasil penelitian bahwa Taman Posyandu Bunda Kartini memperoleh nilai optimal sebagai kriteria penilaiannya. Namun untuk layanan BKB tidak dapat dilakukan secara optimal karena pelaksanaanya tidak dapat dilakukan setiap bulan. Tama Posyandu Bunda Kartini termasuk kedalam UKBM karena dalam pelaksanaannya telah meliputi konsep pemberdayaan yaitu kemandirian, pertisipasi, jaringan kerja dan pemerataan.
\end{abstract}

Kata kunci: Taman Posyandu, UKBM, Pemberdayaan Masyarakat, Promosi Kesehatan 


\section{PENDAHULUAN}

Pembangunan kesehatan menjadi salah satu bagian dari program pembangunan. Dapat dilihat dari kepentingan masyarakat, kegiatan pembangunan kesehatan masyarakat adalah bagian dari kegiatan swadaya masyarakat yang bertujuan meningkatkan kesehatan masyarakat, melalui perbaikan status kesehatan. Untuk mencapai status kesehatan yang baik pada setiap orang, perlu dilakukan upaya untuk memantau pertumbuhan dan perkembangan sejak dini, salah satunya melalui program pemantauan pertumbuhan dan perkembangan anak.

Pemantauan pertumbuhan dan perkembangan tidak hanya meliputi bidang kesehatan tetapi bidang pendidikan dan sosial. Karakter setiap individu dapat dibentuk melalui asupan yang diterima dan sosialnya, oleh karena itu setiap orang memerlukan peman-tauan sejak dini untuk terbentuk individu yang sehat secara fisik, mental maupun sosialnya, sehingga tidak hanya terbebas dari penyakit dan kecacatan.

Salah satu upaya untuk memantau pertumbuhan dan perkembangan anak adalah dengan dibentuknya program Taman Posyandu. Taman Posyandu adalah program yang dibentuk oleh Pemerintah Provinsi Jawa Timur, dimana program ini merupakan layanan posyandu yang terintegrasi dengan Pendidikan Anak Usia Dini (PAUD) dan Bina Keluarga Balita. Taman Posyandu adalah pengembangan posyandu berstrata purnama atau mandiri yang diberi tambahan layanan Pendidikan Anak Usia Dini (PAUD) dan pengasuhan balita yang diperoleh melalui Bina Keluarga Balita, sehingga balita mendapat pelayanan secara menyeluruh mulai dari kesehatan, pemenuhan gizi, pola asuh, dan perlindungan terhadap anak.

Tahun 2013, Pemerintah Provinsi Jawa Timur mencanangkan membentuk 10.000 Taman Posyandu, pada akhirnya terbentuk 10.927 Taman Posyandu di seluruh Provinsi Jawa Timur. Kota surabaya menjadi salah satu kota yang memiliki Taman Posyandu terbanyak di Provinsi Jawa Timur. Pada tahun 2017 telah terbentuk 100 Taman Posyandu baik yang sudah optimal maupun yang belum optimal. Salah satunya adalah Kecamatan Kenjeran yang memiliki enam Taman Posyandu, dimana 5 taman posyandu sudah optimal dan 1 Taman Posyandu belum optimal.

Salah satu puskesmas yang ada di wilayah kerja Kecamatan Kenjeran adalah Puskesmas Sidotopo Wetan yang membina dua Taman Posyandu. Sehubungan dengan itu maka peneliti ingin melihat gambaran pelaksanaan program Taman Posyandu dari salah satu taman posyandu yang terletak di kota surabaya yaitu di Taman Posyandu Bunda Kartini di wilayah kerja Puskesmas Sidotopo Wetan.

\section{METODE PENELITIAN}

Desain penelitian dalam penelitian ini menggunakan desain penelitian deskriptif dan 
observasional, dimana peneliti ini dilakukan dengan mengumpulkan data sekunder dan observasi. Observasi dilakukan dengan mengamati secara langsung pelaksanaan kegiatan Taman Posyandu di wilayah puskesmas Sidotopo Wetan. Tanya jawab dilakukan dengan pihak terkait yaitu kader Taman Posyandu dan pemegang program Promkes Puskesmas Sidotopo Wetan. Tanya jawab dilakukan untuk mengetahui secara jelas gambaran dari pelaksanaan kegiatan, tugas, dan kinerja dari setiap petugas pelaksana program Taman Posyandu.

Dalam penelitian ini peneliti ikut berpartisipasi dengan mengikuti pelak-sanaan kegiatan Taman Posyandu di Taman Posyandu Bunda Kartini yang berada di wilayah kerja puskesmas Sidotopo Wetan. Kegiatan dilaksanakan selama 5 minggu dimulai pada tanggal 13 Agustus 2018 sampai dengan tanggal 13 September 2018.

\section{HASIL DAN PEMBAHASAN}

Puskesmas Sidotopo Wetan merupakan salah satu puskesmas yang terdapat di wilayah Kecamatan Kenjeran. Mempunyai wilayah kerja dengan luas 1,66 km2 yang meliputi satu wilayah kelurahan yaitu kelurahan sidotopo wetan. Terdiri dari 14 rukun warga dengan 149 rukun tetangga. Visi dari puskesmas sidotopo wetan adalah mewujudkan masyarakat yang sehat dengan pelayanan kesehatan yang profesional.

\section{Laporan hasil kegiatan Taman Posyandu di} Puskesmas Sidotopo Wetan

\section{Penilaian Taman Posyandu bunda kartini}

Penilaian taman posyandu bunda kartini dilakukan dengan menggunakan format yang telah tercantum di dalam buku saku tugas pendamping Taman Posyandu. Penilaian ini dilakukan untuk mengetahui apakah kegiatan pemberdayaan masyarakat yang dilakukan di Taman Posyandu Bunda Kartini sudah optimal atau belum optimal.

Tabel 1. Hasil penilaian Taman Posyandu Bunda Kartini

\begin{tabular}{lccc}
\hline Indikator & Posyandu & PAUD & BKB \\
\hline Sarana & $\sqrt{ } \sqrt{ }$ & $\sqrt{ } \sqrt{ }$ & $\sqrt{ } \sqrt{ }$ \\
Kader & $\sqrt{ } \sqrt{ }$ & $\sqrt{ }$ & $\sqrt{ }$ \\
Layanan & $\sqrt{ } \sqrt{ }$ & $\sqrt{ } \sqrt{ }$ & $\sqrt{ }$ \\
Pembinaan & $\sqrt{ } \sqrt{ }$ & $\sqrt{ } \sqrt{ }$ & $\sqrt{ }$ \\
\hline Total & 11 & 10 & 8 \\
\hline
\end{tabular}

Keterangan:

$$
\begin{aligned}
& \sqrt{ } \text { : Kurang } \\
& \sqrt{ } \sqrt{ }: \text { : Baik } \\
& \sqrt{ } \sqrt{ } \sqrt{ }: \text { Sangat Baik }
\end{aligned}
$$

Dari hasil tabel penilaian yang telah dilakukan diperoleh hasil, bahwa dari indikator yang dinilai baik Posyandu, PAUD, dan BKB, Taman Posyandu Bunda Kartini memperoleh hasil optimal. Namun pada pelaksanaan Bina Keluarga Balita belum dapat diberikan layanan dengan optimal, dikarenakan tidak dapat melakukan penyuluhan secara rutin setiap bulan, sementara penilaian dari masing-masing 
sektor yaitu Posyandudan PAUD telah berjalan dengan sangat baik. Adapun penilaian dari masing-masing sektor yaitu Posyandu, Pendidikan Anak Usia Dini (PAUD), dan Bina Keluarga Balita (BKB) meliputi indikator sebagai berikut:

\subsection{Sarana Taman Posyandu}

Sarana taman posyandu dalam keadaan baik dan dapat dipergunakan dengan baik. Mainan untuk kegiatan pembelajaran tergolong lengkap dan dalam kondisi baik. Terdapat 8 orang kader yang hadir dalam pelayanan posyandu dan memberikan pelayanan sebanyak 2 kali setiap bulan. pada minggu pertama dilaksanakan penimbangan dan pada minggu kedua dilaksanakan penyuluhan. Sarana PAUD sudah sangat baik setiap anak berkesempatan bermain dengan lebih dari 2 mainan. Sarana BKB terdapat lebih dari 4 macam, dimana semuanya dalam kondisi baik, tersedia leaflet, poster, dan banner untuk sarana penyuluhan. Berikut kutipan dari narasumber.

"Sarana dalam kondisi baik ada banyak mainan, satu anak bisa main lebih dari 2 mainan. Tapi kekurangannya kita ga punya mainan yang ada di luar ruangan. Dulu sempat punya mainan ayunan, perosotan gitu-gitu di samping balai $R W$, tapi dibuat mainan anak-anak umum soalnya ga ada pagar pembatasnya, jadine mainannya sekarang rusak. Terus ini PAUDnya pinggir jalan raya bahaya juga kalau anak-anak mainan di pinggir jalan, jadi mainnya di dalam kelas saja." (Informan 1)

"Kalau sarana dan prasarana udah baik sih, soalnya kan mereka dapat dana BOP sama dana APBD untuk PAUDnya, kalau yang di posyandu sarananya baik masih layak untuk digunakan." (Informan 2)

Sarana dan prasarana taman posyandu sudah baik karena baik, karena mendapatkan dana BOP dan APBD untuk perawatan sarana dan prasaranayang ada. Sarana penyuluhan seperti poster, leaflet dan banner telah disediakan oleh pihak puskesmas yang diberikan saat akan diadakan kegiatan penyuluhan.

\subsection{Kader Taman Posyandu Bunda Kartini}

Komitmen dari setiap kader dapat dilihat dari kader yang hadir pada setiap kegatan PAUD, posyandu maupun BKB. Kader berasal dari lingkungan sekitar taman posyandu yang berada di RW10. Pada kegiatan PAUD dilaksanakan oleh guru PAUD yang telah terlatih untuk merancang kegiatan pembelajaran dan mampu membuat APE sederhana. Pada kegiatan BKB, kader telah mendapatkan pelatihan terkait penyuluhan yang akan disampaikan pada saat pembinaan BKB. Jumlah kader yang membina Taman Posyandu, dari masing-masing sektor layanan ada 5 kader, dimana 3 orang kader dari PAUD dan 2 orang kader dari posyandu, untuk kader BKB menjadi satu dengan kader Posyandu.

"Kadernya dari warga RW 10
sendiri...bunda PAUDnya bisa mengajar
dengan baik soalnya kan ini ada
bundanya yg kuliah juga, ada 3 bundanya
yang masih kuliah kalau libur ya bisa ikut
ngajar kalau pas kuliah ya ngajar yang
kelas sore." (Informan 1)

"Kadernya dari warga $R W \quad 10$ dengan baik soalnya kan ini ada bundanya yg kuliah juga, ada 3 bundanya yang masih kuliah kalau libur ya bisa ikut kelas sore." (Informan 1) 
"Di Puskesmas Sidotopo Wetan ini ada 13 Tapos tapi yang sudah optimal ada 3, kalo jumlah kadernya yang membina Taman Posyandu ada 2 orang dari posyandu ada 3 orang dari guru PAUD nya sendiri, jadi ya ada 5 lah. Kalau kader BKB sendiri kita ga ada jadi ya jadi satu sama paudnya." (Informan 2)

Kader taman posyandu yang dibentuk telah mempunyai kualifikasi yang baik, dimana sebagian kader yang dipilih memang kader yang sudah punya kompetensi sebagai guru PAUD dan kader posyandu. Serta ada keterlibatan dari pihak kelurahan, puskesmas dan dinas terkait.

"Iya sudah punya kompetensi, kan kalo dari guru paudnya masih ada yg kuliah juga." (Informan 1)

"Ada keterlibatan rw, tenaga promkes, Kapus, gizi, kesling. bikel iya tapi lebih kaya ke yang imunisasi enggak yang mengawasi gitu." (Informan 2)

\subsection{Layanan Taman Posyandu Bunda Kartini}

Tingkat keaktifan Taman Posyandu dapat dilihat dari pelayanan yang dilaksanakan dan jumlah kegiatan pertahunnya. Taman Posyandu bunda kartini mempunyai 7 kader yang aktif di PAUD dan 8 kader yang aktif di posyandu dan BKB. Dalam satu tahun dilaksanakan kegiatan posyandu sebanyak 24 kali, dimana 12 kali dilakukan kegiatan penimbangan dan 12 kali dilaksanakan kegiatan penyuluhan. Kegiatan PAUD dilaksanakan 4 kali dalam satu minggu. Pada kegiatan BKB telah dilakukan penyuluhan, akan tetpi pelaksanaanya belum dapat dilakukan rutin setiap bulan karena keterbatasan waktu dan tenaga. Pelayanan konseling dan rujukan telah mampu dilakukan oleh kader taman posyandu bunda kartini, untuk konseling terkadang dilakukan setelah kegiatan mengajar di PAUD yang ditujukan langsung kepada ibu balita. untuk pelaksanaan rujukan, kader akan segera merujuk ke puskesmas apabila ditemukan kasus, seperti kasus berat badan balita di bawah garis merah maupun gizi buruk. Berikut ini pemaparan dari narasumber.

"Disini BKBnya berjalan tapi ya ndak bisa rutin setiap bulan, kadang kalau ada anak yang bermasalah gitu atau pas selesai sekolah ibuk-ibuknya dikasih penyuluhan, dikasih tahu perkembangan anaknya, terus penyuluhan bagaimana mendidik anak dengan baik, bagaimana mengatasi diare gitu, itu materinya juga diambil kalau ada penyuluhanpenyuluhan dari puskesmas itu. Kalau bunda paudnya bisa mengajar dengan baik soalnya kan ini ada bundanya yg kuliah juga, ada 3 bundanya yg masih kuliah kalau libur ya bisa ikut ngajar kalau pas kuliah ya ngajar yang kelas sore." (Informan 1)

"Kalau posyandu setiap bulan dilakukan 2 kali, setiap kamis pertama sama kamis kedua, kalau kamis pertama penimbangan, kamis keduanya penyuluhan. Kalau PAUDnya ini kan ada kelas pagi sama kelas siang, yang kelas pagi seminggu 4 kali hari senin, rabu, kamis, jumat. Kelas sore seminggu 3 kali hari senin, rabu, jumat. (Informan 1)

"Pelayanan Taman Posyandu rutin dilakukan setiap bulan, seperti PAUDnya ini berjalan rutin tidak ada kendala, kemudian posyandunya juga rutin sebulan 2 kali, hanya saja BKBnya yang 
belum bisa rutin, soale aku juga gak selalu bisa dateng kalo pas ada BKB." (Informan 2)

\subsection{Pembinaan Taman Posyandu Bunda Kartini}

Taman Posyandu merupakan posyandu yang terintegrasi dengan PAUD dan BKB, mak perlu dilakukan pembinaan dari lintas sektor. Pada dasarnya kegiatan taman posyandu merupakan kegiatan yang dilakukan oleh masyarakat dan untuk masyarakat, yang membutuhkan dari pihak terkait untuk membentuk kemandirian masyarakat. Berdasarkan informasi dari narasumber tman posyandu bunda kartini telah mendapatkan nilai optimal sehingga sudah tidak dilakukan pembinaan, tetapi setiap bulan kader melakukan pelaporan pada pihak puskesmas dan dinas pendidikan. Berikut pemaparan dari narasumber.

"Tahun ini sudah ga dilakukan pembinaan, tapi setiap bulan kita laporan ke puskesmas sama dinas pendidikan."

"Tahun lalu kalau dari puskesmas jarang paling 3 bulan sekali, kalau tahun ini sudah enggak ya tinggal laporan-laporan aja." (Informan 1)

"Untuk Kapus terlibat langsung juga sih dipembinaannya, dari aku pj promkesnya, ada pembinaan dari dinas pendidikan juga, kalo BKB dapat juga dari pkk kelurahan tapi jarang banget... terus Pembinaanku ga bisa yg tiap bulan sekali, paling 3 bulan sekali, soalnya banyak yg taposnya diadakan sore jadi aku gak bisa datang." (Informan 2)

\subsection{Kebijakan Dalam Pelaksanaan Taman}

\section{Posyandu}

Dalam pelaksanaan Taman Posyandu Bunda Kartini di RW 10 Kecamatan Sidotopo Wetan, dibentuk kebijakan dalam bentuk Surat Keputusan (SK) pembentukan taman posyandu. Surat Keputusan dibuat langsung oleh ketua RW dan disahkan kepala Kelurahan Sidotopo Wetan. Pihak puskesmas tidak mempunyai kebijakan khusus terkait pelaksanaan taman posyandu yang telah dilakukan pembinaan. Berikut pemaparan dari narasumber.

"Kalau SK kita ada SK mbak, tapi ini Sknya di bawa sama bunda PAUD" (Informan 1)

"Kalau dari kita puskesmas ga ada kebijakan tersendiri dek, soalnya kan sejak aku ditugaskan di sini itu taman posyandu itu sudah terbentuk, jadi kita udah tinggal melakukan pembinaan. terus kita juga ga berani ikut campur sih kalo maslah itu, kan itu kewenangan mereka kalo kita ikut campur terlalu jauh takutnya malah mengganggu, jadi yaudah berjalan kaya gini aja, kita pembinaan aja." (Informan 2)

\subsection{Kendala Yang Dihadapi Dalam Pelaksanaan Taman Posyandu}

Pada pelaksanaan dan pembinaan Taman Posyandu Bunda Kartini, tidak ditemukan banyak kendala. Taman posyandu dibina telah rutin melakukan pelaporan pada pihak puskesmas. Tetapi dalam pelaksanaan pendampingan yang dilakukan oleh penanggung jawab Program Promosi Kesehatan Puskesmas Sidotopo Wetan adalah masih terkendala waktu 
dan tempat. sedangkan kendala yang dihadapi kader taman posyandu dalam pelaksanaan dan pembinaan, masih pada UMKM yang ditunjuk untuk membuat PMT balita, karena sering mengalami keterlambatan dalam pengiriman. Berikut ini pemaparan dari narasumber.

"Kendalaku ya di itu tadi ya di waktu, soalnya kebanyakan yang sore sedangkan ada 13 tapos itu juga belum semua di bina, soalnya kalo aku ada pembinaan kan ada transport kadernya, kalo gak ada ya aku gak ngelakuin pembinaan. Soalnya gak enak juga membebankan pekerjaan ke mereka, kalo aku bina sendiri juga ga bisa soalnya ada pekerjaan lain juga kan." (Informan 2)

"Alhamdullilah.... kalau di PAUD sudah baik sudah lancar, untuk transport sudah tidak ada kendala kan sudah diambilkan dari dana spp siswa itu atau dari BOP itu, kalau dulu waktu awal-awal itu untuk transport masih ada bantuan dari iuran $R T$ mbak tapi sekarang kan sudah ada uang spp sama dana BOP itu jadi lebih enak. Dari belajar mengajar juga sudah ga ada kendala, tapi ya ada beberapa orang tua yang gak mau bawa anaknya ke paud pagi soalnya kan ada orang tuanya yangg bekerja. Tapi kalo dari $R W$ sudah diberitahukan ke warga-warga kalau RW kita punya PAUD, jadi warganya itu kalo bisa ya bawa nakanaknya ke PAUD. Kalo di posyandu apa ya... Cuma dari UKMnya itu sering telattelat ngantar makanannya, jadi kan ibuibu itu pada gak sabar kalo suruh nunggu. Kalau warga yang datang banyak, alhamdullilah warganya antusias sih mbak." (Informan 1)

"Ga ada sih, soalnya mereka juga udah rutin melakukan pelaporan, biasanya yang laporan itu salah satu dari kader posyandu atau dari bunda paudnya, atau biasnya aku ngambil dari bunda paud yangg merangkap kader posyandu. Terus banyak juga kader yang udah lanjut usia, jadi kalo dapat informasi kan agak sulit juga, jadinya susah untuk membagi ke teman-temannya." (Informan 2)

\subsection{Rencana Intervensi Untuk Pelaksanaan Dan Pembinaan Taman Posyandu}

Rencana intervensi kedepan untuk pembinaan taman posyandu, akan dilakukan pendampingan dengan lebih rutin terutama untuk pendampingan BKB. Berikut pemaparan narasumber.

"Intervensi kedepannya, kalo untuk tapos yang belum optimal intervensinya lebih kaya ke nitip materi, atau nitip mediake mereka soalnya itu kan lebih banyak dipegang $R W$ jadi kita belum bisa banyak terlibat, soalnya kan kewenangan $R W$. Kalo BKB masih diusahakan untuk bisa hadir sih soalnya kalo dulu kan petugas Promkesnya masih sedikit, tapi kalo sekarang kan udah ada promotor jadi nanti rencanya aku bagi tugas sama promotornya." (Informan 2)

\section{Strategi Promosi Kesehatan Menurut WHO}

Startegi promosi kesehatan yang dilakukan dalam pelaksanaan program taman posyandu bunda kartini di kelurahan sidotopo wetan, dilaksanakan sesuai dengan strategi global promosi kesehatan menurut WHO 1984 yang meliputi advokasi, dukungan sosial, dan pemberdayaan masyarakat.

\section{Advokasi (Advocacy)}

Advokasi merupakan kegiatan yang ditujukan kepada pembuat keputusan atau penentu keputusan (policy maker) baik dalam 
sektor kesehatan maupun di sektor lain di luar kesehatan. Tujuannya dari advokasi adalah agar pembuat keptusan mengeluarkan kebijakankebijakan, yang berupa peraturan undangundang, instruksi dan sebagainaya yang dapat menguntungkan kesehatan publik.

Pelaksanaan program Taman Posyandu di wilayah kerja Puskesmas Sidotopo Wetan bentuk advokasi yang dilakukan adalah dengan melakukan advokasi pada pembuat keputusan. Dalam hal ini adalah kepala kelurahan dan ketua RW di Kelurahan Sidotopo Wetan. Dimana kepala kelurahan dan ketua RW disini sebagai pembina dari taman posyandu, mempunyai kewenangan untuk membina posyandu yang ada di wilayah kerjanya.

Bentuk-bentuk kegiatan advokasi antara lain dengan lobying, pendekatan atau dengan pembicaraan baik formal maupun nonformal terhadap pembuat kebijakan keptusan, dengan menyajikan masalah kesehatan atau yang mempengaruhi kesehatan masyarakat setempat, dan sebagai-nya. Dari advokasi yang dilakukan akan menghasilkan kegiatan atau peraturan, instruksi terkait dengan masalah kesehatan.

Hasil advokasi yang telah dilakukan pada kepala kelurahan dan ketua RW menghasilkan adanya Surat Keputusan (SK) pembentukan Taman Posyandu Bunda kartini, akan tetapi pihak puskesmas tidak mempunyai pertaturan tersendiri yang terkait dengan kegiatan taman posyandu.

\section{Dukungan sosial (Social Support)}

Dukungan sosial merupakan kegiatan yang ditujukan kepada tokoh masyarakat baik secara formal maupun informal yang dapat berpengaruh di masyaraka. Tujuan dai adanya dukungan sosial adalah agar kegiatan atau program kesehatan tersebut mendapatkan dukungan dari tokoh masyarakat. Selanjutnya tokoh masyarakat diharapkan dapat menjembatani atara pengelola program kesehatan dengan masyarakat.

Pelaksanaan program taman posyandu bunda kartini telah menda-patkan dukungan dari tokoh masyarakat, Baik dalam bentuk materi maupun melakukan sosialisasi adanya kegiatan Taman Posyandu pada masyarakat. Awal pembentukan taman posyandu, mendapatkan dukungan dari dana kas masing-masing RT di wilayah RW 10 Kelurahan Sidotopo Wetan. saat ini dukungan dalam bentuk materi sudah tidak diberikan karena taman posyandu telah mendapatkan biaya operasional baik dari dinas kesehatan maupun dinas pendidikan. Selain itu ketua RT dan pengurus PKK juga melakukan sosialisasi pada masyarakt yang mempunyai balita untuk mengikuti kegiatan taman posyandu, mulai dari posyandu, PAUD dan pembinaan $\mathrm{BKB}$.

\section{Pemberdayaan Masyarakat (Empowermet)}

Pemberdayaan masyarakat ditujukan kepada masyarakat langsung, sebagai sasaran utama promosi kesehatan. Tujuan dari pemberdayaan masyarakat agar masyarakat 
memiliki kemampuan dalam memeliharadan meningkatkan kesehatan mereka sendiri. Kegiatan pemberdayaan masayarakat lebih pada kegiatan penggerakan masyarakat untuk kesehatan. Taman Posyandu merupakan salah satu bentuk UKBM yang dibentuk atas dasar kebutuhan masyarakat, dikelola oleh masyarakat, dari masyarakat dan untuk masyarakat dengan adanya bimbingan dari puskesmas dan lintas sektor. Taman Posyandu merupakan pengembangan dari posyandu berstrata purnama atau mandiri yang terintegrasi dengan layanan pendidikan anak usia dini (PAUD) dan pengasuhan balita oleh orang tua yang mendapatkan pendampingan dalam kelompok bina keluarga balita (BKB). Pada taman posyandu dilaksanakan pembinaan anak secara utuh, sehingga pembinaan pada balita tidak hanya dilakukan sendiri oleh orang tua tetapi ada intervensi dan mendapatkan fasilitas dari pemerintah melalui kerja sama dengan lembaga atau lintas sektor.

Sebelum ditetapkan sebagai taman posyandu, pemerintah kota surabaya telah membentukprogram pos paud terpadu yang tercantum dalam Peraturan Walikota Surabaya No. 20 Tahun 2008 menyatakan bahwa pos pelayanan terpadu merupakan salah satu bentuk UKBM untuk meningkatkan kemampuan masyarakat dalam membangun, menyelenggarakan dan mengembangkan usaha kesehatan untuk mencapai derajad kesehatan yang baik, sehingga dibutuhkan adanya kegiatan pember- dayaan masyarakat. Pemberdayaan tidak hanya sebuah konsep pembangunan ekonomi tetapi juga meliputi nilai-nilai sosial. ${ }^{1}$

Menurut Craig dan mayo konsep pemberdayaan termasuk ke dalam pengembangan masyarakat dan terkait dengan konsep kemandirian (self help), Dalam kegiatan taman posyandu ini, konsep kemandirian sesuai dengan sasaran taman posyandu yang ditujukan pada posyandu tingkat purnama atau mandiri. Tujuan dari pemilihan kedua strata posyandu ini diharapkan dapat meningkatkan kinerja yang sudah ada. Sehingga kegiatan pemberdayaan dilakukan sesuai dengan kemampuan posyandu agar dapat melaksanakan program taman posyandu secara maksimal. partisipasi (participation), partisipasi masyarakat dapat dilihat dari jumlah kader yang terlibat dalam pelaksanaan taman posyandu dan adanya partisipasi dari pihak puskesmas, tokoh masyarakat dan masyarakat secara lansung. jaringan kerja (networking), adanya jaringan dalam pelaksanaan taman posyandu sangat dibutuhkan, hal ini dapat dilihat dengan adanya pertemuan lintas sektor baik di tingkat kelurahan maupun kecamatan yang bertujuan untuk meningkatkan jaringan kerja antar sektor agar mudah dalam melakukan koordinasi pelaksanaan taman posyandu dengan meningkatkan peran masing-masing sektor. pemerataan (equity), konsep pemerataan diperlukan untuk meningkatkan kemampuan dan kapasitas sumberdaya yang ada. 


\section{SIMPULAN DAN SARAN}

Taman posyandu Bunda Kartini berada dalam wilayah kerja Puskesmas Sidotopo Wetan, yaitu di Kelurahan Sidotopo Wetan. Berdasarkan penilaian taman posyandu bunda kartini sudah termasuk dalam Taman Posyandu yang optimal. Dimana penilaiannya meliputi 3 kegiatan yaitu posyandu, PAUD dan BKB. Namun untuk kegiatan layanan BKB tidak memungkinkan untuk dilaksanakan secara optimal karena pelaksanaanya tidak dapat dilakukan setiap bulan, dan kader BKB masih kurang paham tentang konsep BKB. Taman posyandu bunda kartini merupakan salah satu bentuk UKBM yang melaksanakan kegiatan pemberdayaan masyarakat. Konsep pemberdayaan termasuk dalam pengembangan masyarakat dan terkait dengan konsep kemadirian, partisipation, jaringan kerja, dan pemerataan.

\section{REFERENSI}

1. Wrihatnolo, R.R \& Riant N.D. Manajemen Pemberdayaan Sebuah Pengantar Dan Panduan Untuk Pemberdayaan Masyarakat. Jakarta: PT Elex Media Komputindo. 2007.

2. Badan Pusat Statistik Kota Surabaya. Profil Kesehatan Kota Surabaya: pemeritah kota Surabaya. 2017.

3. Dinas Kesehatan Provinsi Jawa Timur. Buku Pedoman Pengukuran Tingkat Perkembangan UKBM: dinas kesehatan provinsi jawa timur. 2016.

4. Dinas Kesehatan Provinsi Jawa Timur. Petunjuk Teknis Taman Posyandu di Jawa Timur. Dinas kesehatan provinsi jawa timur. 2015.
5. Dinas Kesehatan Kota Surabaya. Buku Saku Tugas Pendamping Taman Posyandu. Surabaya: dinas kesehatan kota Surabaya. 2014.

6. Mardikanto, Totok dan Poerwati S. Pemberdayaan Masyarakat Dalam Perspektif Publik. Bandung: Alfabeta. 2012.

7. Notoatmodjo, S. Promosi Kesehatan dan Perilaku Kesehatan. Jakarta: Rineka Cipta. 2012.

8. Profil Puskesmas Sidotopo Wetan. 2017

9. Alfitri. Community Development Teori dan Aplikasi. Jakarta: Pustaka Pelajar. 2011. 